\title{
New Landscape Conceptualization as a Guideline for Spatial Development: a Case Study from Serbian Spatial Planning Practice
}

\author{
Vladimir Pihler ${ }^{A}$, Nevena B. Vasiljević ${ }^{*}$, Dejan Đorđević ${ }^{B}$, Luka Bajićc ${ }^{C}$ Dragana Dunčić ${ }^{B D}$ \\ Received: January 5, 2021 | Revised: March 31, 2021 | Accepted: April 09, 2021 \\ doi: $10.5937 / g p 25-30177$
}

\begin{abstract}
This paper is focused on clarification of the basic principles for the establishment of an innovative approach in the field of landscape research through its application in spatial planning documents in Serbia. The key question is: how the practice of considering landscape character could direct new spatial arrangements, based on the development of strategic spatial planning documents? The paper describes the results of analysis undertaken during the development of the "Spatial plan for a special-purpose area The Cultural Landscape of Sremski Karlovci". The landscape character assessment was the main methodology taken to define value of landscape character as the starting point for defining border of cultural landscape and "representative landscape units", as well as for guiding sustainable land use management which is opposed to the traditional approach of land-use decision making. Based on landscape character value, this research provides the elements for creating a different conceptual framework for spatial planning in Serbia which is one of the most effective model of the implementation of the European Landscape Convention.
\end{abstract}

Keywords: Landscape conceptualization; landscape character; strategic spatial planning; European Landscape Convention

\section{Introduction}

The spatial transformation processes has impacted upon change in landscape pattern resulting in a loss of landscape character and recognizable identity. The causes and consequences of this loss of diversity have become a subject of interest among researchers, planners and policy makers (Council of Europe, 2000; Antrop, 2000; Van Eetvelde \& Antrop, 2007; Selman, 2006; 2010). There have been extensive research on approaches to landscape analysis, in particular development of methods through spatial planning practice
(De Montis, 2014). The research on the specific character of European landscapes and the modalities of protection within the framework of spatial planning and management are the focus of the European Landscape Convention (ELC) (Council of Europe, 2000). It is explicitly based on sustainable development, highlighting its spatial dimension and spatial planning principles.

Contemporary theories consider the landscape as a holistic, hybrid entity in which natural and cultur-

\footnotetext{
A University of Belgrade, Faculty of Forestry, Department of Landscape Architecture and Horticulture; Spatial planner at the Urban and Spatial Planning Institute of Vojvodina, Novi Sad; pihlervladimir@yahoo.com; nevena.vasiljevic@sfb.bg.ac.rs

B University of Belgrade, Faculty of Geography, Department of Spatial planning; dejandj@gef.bg.ac.rs

C University of Novi Sad, Faculty of Agriculture, Department of horticulture and landscape architecture; luka.bajic@polj.uns.ac.rs

D Urban and Spatial Planning Institute of Vojvodina, Novi Sad; duncicd@gmail.com

* Corresponding author: Nevena Vasiljević; e-mail: nevena.vasiljevic@sfb.bg.ac.rs; tel.: +381-64-1153-857
} 
al processes are unified and where economic, social and environmental objectives become intertwined in a sustainable spatial development approach (Ahern, 2011; Antrop, 2006a; Mayer, 1997; Selman, 2006, 2010; Steinitz, 2005). The starting point for landscape research, seen as an important part of contemporary spatial development activities, is recognition of the landscape evaluation processes. In line with changes in the contemporary spatial planning paradigm towards integration of spatial planning and environmental policies (Van den Broeck, 2004), understanding and interpreting landscape is becoming a medium for integration of dynamic spatial change.

This standpoint has stimulated efforts towards the development of modalities for the assessment of landscape character as an important tool for a spatial analysis. Landscape character assessment is, therefore, to purposefully identify and assess social, cultural, economic and environmental interactions and relationships in order to determine a value in a particular context. As a result, landscape assessment activities are shifting from the identification of "extraordinary landscapes" towards all landscapes which in general represent the context-responsive environment. As such it is no longer purely the subject of research, but also an important operational and strategic instrument for spatial planning (Vasiljević, 2018).

The strategic planning approach offers a good basis for applying landscape thinking to regional planning, due to its distinct processes: a dynamic and sustainable long-term perspective, process-supporting actions, a decision-making process involving all possible actors, and a process of empowering people to improve their living conditions and participate in society (Semančíková, 2007). Research has shown that strategic spatial planning, as a framework for landuse distribution has the capacity to integrate diverse sectoral objectives and bring them closer to one another (Antrop, 2000; Roe, 2008; Pihler et al., 2013; Selman, 2006).

Our argument is that landscape characterization has a potentially important role to play in operationalizing strategic spatial development, but that current approaches to spatial planning practice are not utilizing this potential. The challenge for spatial planning practice is how to determine a set of landscape objectives in relation to different sectoral interests (infrastructure, forestry, agriculture, energy, etc.). That affect the distribution of different land-use and combinations of landscape elements, which make a par- ticular contribution to distinctive landscape character. Since the landscape approach to spatial planning involves the identification and understanding of complex relations between spatial systems, the integration of landscape assessment into planning documents can be seen as an essential framework for spatial management. We came to this conclusion primarily as spatial planners, recognizing the importance of situating constituting spatial elements in their own landscape and realizing that this dimension was often inadequately, or not at all, reflected in current spatial planning approach in Serbia. Therefore, the new challenges and new opportunities for Serbian planners is to place landscape formulations at the cross-point of spatial planning, community management and activities related to enhancement of environmental quality (Pihler et al., 2017).

Ratification of the ELC in 2011 created a more favorable context for Serbian planners to apply the holistic approach of landscape conceptualization which has been implemented in The Spatial Plan of the Republic of Serbia for the period from 2010 to 2020. Legislative measures for the implementation of The Spatial Plan of the Republic of Serbia for the period from 2010 to 2020, foresee the development of landscape character assessment at the regional and local spatial planning levels. There is also a growing trend towards area-specific regional development planning practice which is reflected through the elaboration of a number of Spatial Plans for special-purpose area. This type of planning documents accommodates new ideas on spatiality which is an improvement compared to traditional, sectoral planning documents.

The general objectives of this research is to present the conceptual framework for the interpretation of the Cultural landscape of Sremski Karlovci and the way landscape character assessment has been implemented in the Spatial plan for this special-purpose area It is the first Spatial planning document in Serbia to take landscape characterization approach with the aim to emphasize the value of landscape character as the basis for: a) defining boundary of cultural landscape; b) defining 'representative landscape units', as a special purpose areas; c) setting the planning objectives according to 'landscape quality objectives'. Finally, we believe that contribution of this paper is to point out to the ground for transformation of spatial planning practice in Serbia which is aiming to realize the full potential of landscape characterization. 


\section{Materials and Methods}

\section{Study area}

Sremski Karlovci is an important historical town on the right bank of the Danube between Novi Sad and Belgrade (Figure 1). The town developed into an important cultural and economic hub after 1699 and the signing of The Treaty of Karlowitz. For two centuries it was the main engine of Serbian cultural and religious life. The town developed between the Danube river and the slopes of the Fruska gora mountains (which today hold the status of a national park), constantly balancing between several natural restrictions such as frequent flooding and landslides. tackled by the regional government and most recently the town was strategically designated as part of the area that represents European Capital of Culture in 2021 (together with the city of Novi Sad and two more municipalities).

The area considered by the planning document covered $64,16 \mathrm{~km}^{2}$ containing the diverse landscapes of the forested slopes of the Fruska gora massif and one of the widest alluvial plains of the middle Danube (Special Nature Reserve Koviljsko-petrovaradinski rit). The contact zone between these two dominant spatial entities has determined the specific

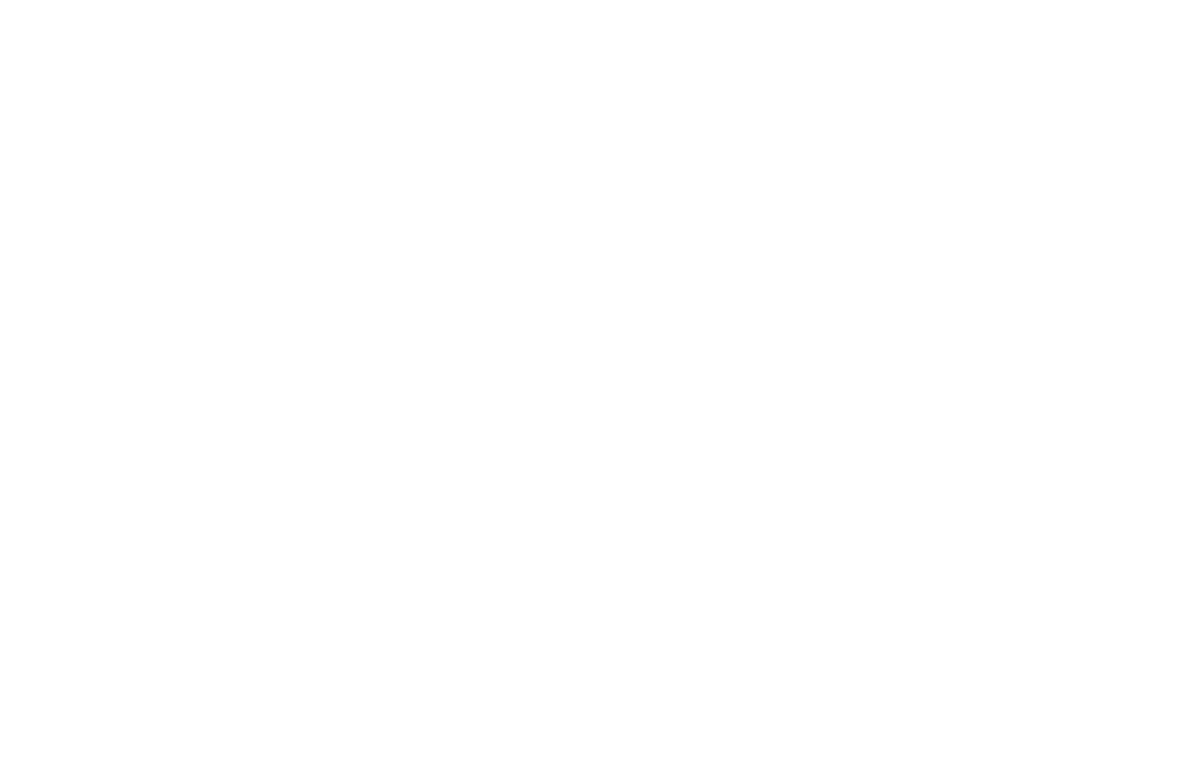

Figure 1. The position of Sremski Karlovci in the regional context. Basemap source: ESRI World Topographic Map [click on figure to enlarge]

Besides multi-layered cultural and natural values, the importance of the area rests on the unique insight into the historical processes of migration and settlement within the Habsburg Empire and the aspirations for disparate groups towards political and religious autonomy.

In the previous century geopolitical changes led the town to decay, causing imbalances in the landscape quality and the overall quality of life. The lack of adequate development strategies and gaps in the national and local legislation further exacerbated this deterioration. Demographic change and the formation of urban sprawl of the city of Novi Sad throughout last decades triggered transformations of the landscape character of Sremski Karlovci and its hinterland. Although the town and its community showed significant resilience sustaining itself through local initiatives, the fear of accelerated deterioration has been form of the landscape characterized by the compact morphology of the historical settlements of Sremski Karlovci and Bukovac and the particularities of their agricultural surroundings. The settlement structure is characterized by a rural matrix, traditionally dependent on the agrarian hinterland and adaptation to the morphology of the erosive relief of the highly fertile slopes of the Fruska gora (Spatial Plan for the Special Purpose Area "The Cultural Landscape of Sremski Karlovci”, 2017).

\section{Methods}

The methodological approach for the development of the spatial planning solutions was based on the decision to incorporate landscape considerations in the spatial planning process by conducting landscape character assessment (LCA) for the selected area according to the techniques and criteria provided by the 
general methodology of landscape characterization (Swanwick, 2020).

The objective of LCA application was to move from the descriptive types of spatial analysis towards more action-oriented analysis (Antrop, 2006b). This approach involved a site-selection analysis which viewed a landscape unit as a potential site for a specific development and protection measures. The question addressed here was "How do we classify homogeneous areas or delineate landscape in order to find the best possible sites with the best potential to represent landscape characteristics of the area designated as a cultural landscape". The "nested hierarchical approach" was taken for the area classification. The classification into homogeneous areas took place on two or more levels. The diversification of the landscape composition at the regional scale was defined in relation to the value of the homogeneity of the landscape structure (represents the nonspatial aspect of a landscape- number and abundance of landscape elements). The diversification of the landscape configuration, at the local scale, was defined in relation spatial arrangement and context of the specific and unique landscape elements. Landscape character means distinctiveness of the landscape pattern which was simultaneously formed by: "contrasting" geomorphologic features, configuration of relief and hydrographic features, spatial arrangement of vegetation and land use, spatial arrangement of the cadastral parcels, settlement structure, road links, rail infrastructure and rural byways, visual arrangement of landscape features and administrative units.

The indicated elements were combined to define the landscape character types (that feature on regional scale) and landscape units (on the local scale). A landscape unit is understood here as a combination of elements that generates, on the local scale, a par- ticular, visible physiognomy, a distinguishable and differentiable morphological and functional arrangement which makes one part of the territory different from another. This understanding of a landscape unit implies that an individual physiognomy - a specific arrangement and combination of the parts defining the appearance of a territory and granting it its special character- may be seen as an "illustration" of the territory. Landscape character types were identified at the scale 1:25,000, while landscape units identification and profiling were treated at the scale 1:10,000.

The procedure involved both the office and field work. The draft for the delineation was prepared at the office based on GIS juxtaposed digital cadastral maps and topographic maps on a scale of 1:25,000 and 1:10,000 with generated clear terrain contours. To enhance the classification into homogeneous areas, the analysis also included same-scale 18 and 19 century historical Austro-Hungarian military maps (Mapire, 2014), soil maps and geomorphologic maps. The boundaries of each landscape area were checked and modified through the field work and the draft classification of landscape types and units was validated. Following the field work, single GIS geo-data-base containing multiple features on landscape types and units was merged and applied to generate maps presenting multiple landscape unites combined into 3 landscape types, each with its own distinctive character. The final product of the analysis was a selection and description of landscape units that figured as the "illustration" of the territory and its major landscape types. Maintaining their stability was the main task for the spatial planning directives (land use change, development guidelines and measures for protection, construction regulation and development priorities) and guidelines for proper realization (implementation) and coordination by regional and local authorities.

\section{Results}

According to the performed methodology of landscape character assessment, the Spatial Plan for Special Purpose Area defined 3 landscape types at the regional scale, and 9 (nine) landscape representative units at the local scale, which are meant to provide a synthetic, but sufficiently detailed view of the region's landscape configurations and they provide a good reflection of its cultural profile (Table 1: Figure 2). Each unit is the outcome of a group of landscape units which landscape features are repeated in the territory and together form one of 3 identified landscape types at the regional scale.

The Danube River with its inundation area includes a unique water-scape (ecosystem) that (together with
Table 1. Landscape types and representative landscape units

\begin{tabular}{|l|l|}
\hline Landscape types & Representative landscape units \\
\hline \multirow{4}{*}{$\begin{array}{l}\text { The landscape of } \\
\text { the arable slopes of } \\
\text { the Fruska gora with } \\
\text { settlements }\end{array}$} & 1. City center of Sremski Karlovci \\
\cline { 2 - 2 } & 2. West approach from Tekija \\
\cline { 2 - 2 } & 3. East approach from Banstol \\
\cline { 2 - 2 } The forested slopes of the & 4. Ešikovac valley \\
\cline { 2 - 2 } Fruska gora National park & 5. Panoramic trail \\
\hline The Danube river with its & 7. Bukovac plateau \\
\cline { 2 - 2 } inundation area & 8. Karlovac riverbank \\
\cline { 2 - 2 } & 9. Boggy trail \\
\hline
\end{tabular}



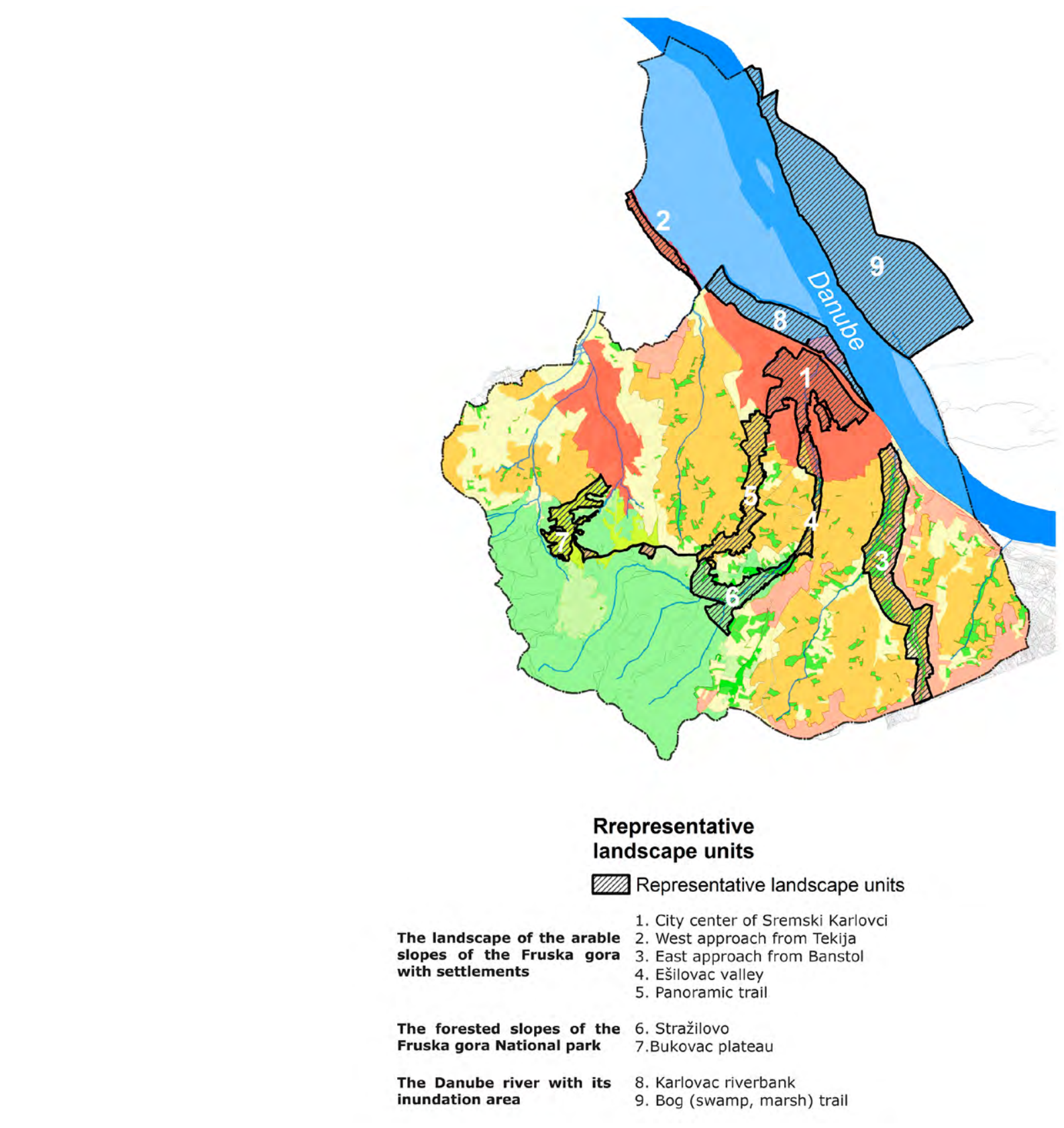

Figure 2. Landscape types and landscape units. Source: The map was created by authors from the GIS database used for the elaboration of the Spatial plan

[click on figures to enlarge]

the main river flow) form multiple branch channels, islands, ponds, swamp forests and shrubs (Figure 3). The magnitude of the Danube, its continuity and cohesion creates the dominant influence on the composition of the structure of this landscape type. In addition to these landscape elements, which are, in origin, close to the natural, integral part of this spatial system is a mosaic of spatial elements of anthropogenic origin: agrarian complexes and agroforestry areas, hydro-technical facilities for flood protection, transport infrastructure and fragments of urban greenery. The configuration of this type of landscape structure belongs to an organic form, primarily created by the changing dynamics of the river banks. This integral organic form is one of the main features of the composition of this type of landscape, and its sensitivity can be expressed through distortion of this configuration, which is the bearer of the diversity of the ecosystem. One of the essential characteristics of this area is the dynamic nature, and seasonal variability of water levels of the river with its periodic extremes.

The composition of the landscape of the arable slopes of Fruska gora with settlements is characterized by the settlements and their hinterlands - agricultural areas of the northern slopes of the mountain range (dominantly composed of vineyards, orchards, 


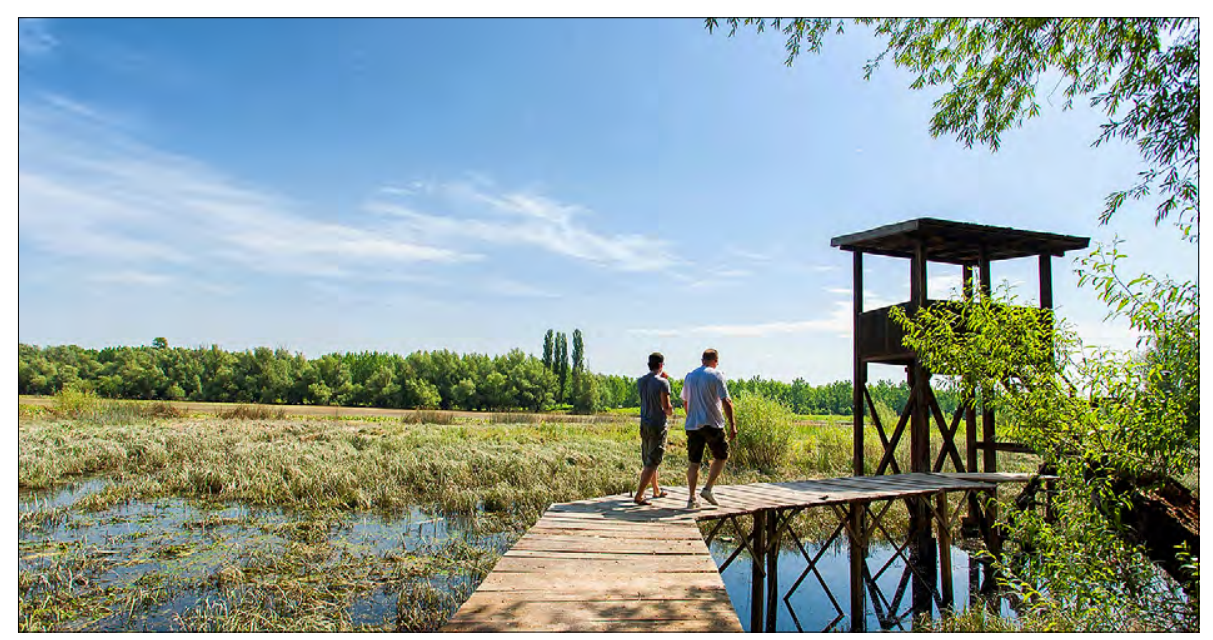

Figure 3. Inundation area of the Danube river Source: Vojvodina Environmental Movement, Sremski Karlovci

fields and fragments of agroforestry). The configuration of this landscape structure is the consequence of the morphology of the terrain formed by the erosion of soils developed from alluvial and proluvial relief, intensive leaching and dredging, descending ultimately to the banks of the Danube. The basic geometry of the terrain is formed of relatively short watercourses which descend vertically from the top to the foot of the hills, forming stream valleys. The first phases of settlement in Bukovac and Sremski Karlovci grew up along these streams (Figure 4). The contemporary structure of the settlements in this area is also characterized by large areas of low density sprawl, consisting of vacation houses developed on relatively small plots of previously agricultural land and not supplied with appropriate infrastructure. The urban sprawl has extended until it is almost continuous between the historical urban agglomerations. This urban expansion occurred over the last decades and was predominantly an informal process which today has become a significant factor in the composition of the region's character. This phenomenon is an indicator of the deteriorated condition and represents a significant deviation from the historical matrix of settlement and land use. The coherence of the elements involved in the composition of the landscape structure (valleys of the watercourses, agricultural area of vineyards and orchards, agroforestry areas, the historical centers of the settlements, urban sprawl), which are the major holders of the identity, represent entities that will have to be considered in the formulation of the cultural landscape. Formulation of the landscape quality objective and the degree of vulnerability of this type of landscape character can be seen through a series of parameters that should be the focus of spatial intervention:

- The configuration of the buildable land structure in terms of the relation between built-up and open space, population density, land use, urban development control, the character of the settlement fronts and the sustainable use of open, green spaces;

- The preservation of agricultural land use for vineyards and orchards;

- The continuity of local ecological corridors as the holders of habitats along watercourses and their capacity to expand and form continuous links between the forest habitats of the Fruska gora and aquatic habitats of the Danube;

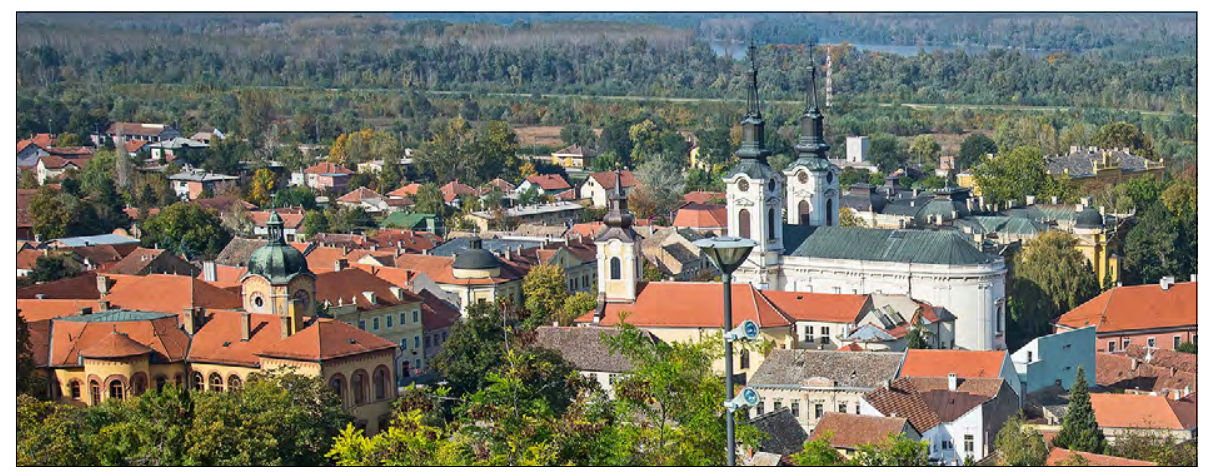

Figure 4. The city Center of Sremski Karlovci (landscape units) Source: Vojvodina Environmental Movement, Sremski Karlovci 
- The control of the urban sprawl expansion and greater control of densification.

The forests of the Fruska gora are deciduous and dominate the composition of the landscape stretching along the mountainous massif. The homogeneous and compact structure of the forest in the east turns into a mosaic structure of alternating complexes of agricultural land, agroforestry areas, arable land, orchards and vineyards that were created on former forest land. The configuration of this type of landscape is formed by a relief of moderate leaching. The geometry of the landscape is formed by multiple stream lines with a through the integration of spatial entities formed by the dominant landscape character of the Fruska Gora, the river Danube and the specific characteristics of the "Vojvodina-Pannonian-Danube macro-region".

- Secondly, 'representative landscape units' were identified and declared as 'special purpose area' with the aim to represents 'landscape quality objectives. Furthermore, the planning document managed to synchronize landscape objectives with the guidelines and measures of different sectoral agendas such as local environmental protection plans, tourism development strategies, agriculture, for-

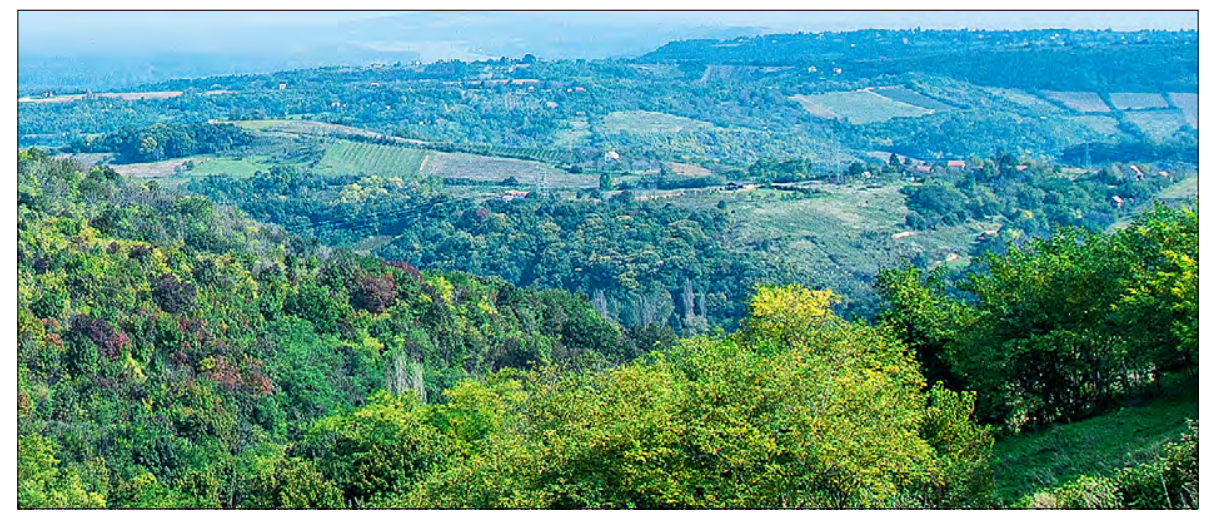

Figure 5. The forested slopes of the Fruska gora National park (landscape type) Source: Vojvodina Environmental Movement, Sremski Karlovci

relatively slow flow. The stability of this type of landscape is indicated by the surface forest cover, its density, the total area of the nature protection zones and the length of the forest edge. Forest areas, as the major holder of this type of the landscape, indicate a potential source of instability: forest vegetation and habitats may not represent the potential natural vegetation, and therefore have an impact on the authentic landscape value.

The purposeful methodology of landscape characterization enabled profiling of certain characteristics as strategically relevant for spatial planning interventions. Landscape character assessment is provided "quality problem identification" which led to the definition of 'the landscape quality objectives'. That generated two crucial elements for the spatial planning document:

- Firstly, the spatial scope of the planning document defined the institutionalized border of the Cultural Landscape of Sremski Karlovci. It appeared to be different from the initial (hypothetical) spatial frame defined by the regional planning board on the initiation stage. The territory is seen as an interaction of spatial elements that appear in a broader spatial context, the meaning of which is defined estry, water management and heritage protection.

As the result of the described methodology, we could conclude that landscape formulations, representative landscape unit and landscape type identification and mapping, are placed at the cross-point of spatial planning objectives - land use change, development guidelines and measures for protection, construction regulation and development priorities. Next to the technical specification for each landscape unit, as a strategic tools, the planning document provided systematic development guidelines and protection measures, related to the multiple components that form the main landscape character value such as: land use (existing structures, possible alterations, compatible use), building parameters, vegetation, heritage features, morphological aspects of agricultural parcels (size, accessibility), urban parameters (density, heights, regulations, accessibility to hinterland) roads and rural byways, dynamics of change and other relevant spatial arrangement data. Guidelines are designed to serve the local authorities in the spatial development planning processes and frameworks (urban planning, forestry planning, environmental and nature protection, etc.). 


\section{Discussion}

The landscape characterization provided identification of landscape types and representative landscape units on different scale levels and gave sufficiently detailed assessment of the territory as a whole. It determined what were important features of the landscape and why. The quality objectives in order to be meaningful were linked to particular problems of landscape quality. Scientific literature frequently mentions the ability of spatial planning to place landscape quality objectives in the context of social, cultural, economic and environmental problems (Ahern, 2011; Selman, 2010; Vasiljević, 2018). The methodology of landscape character assessment, implemented through the elaboration of the Spatial Plan for the Special Purpose Area of the Cultural Landscape of Sremski Karlovci, enabled the merging of landscape objectives with the guidelines and measures of different sectoral agendas such as environmental protection plans, tourism development strategies, agriculture, forestry, energy, natural and cultural heritage protection. This provided the basis for defining land use assessments, building parameters and sectoral development plans.

In line with the presented approach, the concept of spatial development of this area will focus on: the preservation of functionality, diversity and the visual experience of the landscape form, better articulation of land use to safeguard the area against uncontrolled constructions, infrastructure improvements, arrangement of historical settlement cores, continuous functional connections between the forests of the Fruska gora and the Danube, development of recreational areas and educational pavilions integrated with the protection of natural and cultural resources and the Fruska gora National park.

Landscape character approach enabled the changing of the border, in which, the cultural landscape of Sremski Karlovci has been seen as a multifunctional spatial entity, and its formation is considered as a public interest in the field of culture, ecology and the environment, as well as at the social level. Accordingly, the landscape character as a major part of the cultural identity is seen as a public domain, and its improvement is in the interest of all participants in the planning process. The design concepts and visions proposed by the planning document look for spatial interventions which do not consume the potential of the territory but rather irrigate the territory with potential as Kollhaas (1995) and Corner (2006) disused within researches regarding future of sustainable urban planning. Extracted landscape units were taken on the basis of strategic choices, as surfaces that have the capacity to be examples which emphasize operational logic over direct compositional design.

By touching on policy domains, over the course of this research, the discussion will also serve to underline the effort put into establishing changing arrangements between institutional frameworks in different sectors: cultural and natural heritage management, water and infrastructure management, spatial planning and environmental protection. According to Giddens (1984:227), "institutional change is mostly a process of gradually altering interactions that is resulting in new policy practices with the aim to promote and institutionalize new policy concepts that will lead to the re-articulation of policy arrangements".

\section{Conclusion}

This research gives an overview of contemporary landscape conceptualization that has been read and interpreted in a holistic manner as a multifunctional and multidimensional entity the character of which should be protected and enhanced according to local and regional values, while challenging current development trends. Landscape unit and landscape type identification and mapping were the basis for spatial development guidelines based on qualitative indicators, value and quality objectives for future development.

The development of the Spatial planning document is interpreted in this paper in relation to the Serbian spatial planning systems' ability to recognize landscape character assessment as an important activity and a valid approach in guiding spatial development. Through the analysis of the results of the landscape conceptualization approach, it has been confirmed that spatial change can be directed through considerations of landscape dynamics where landscape character represents the major medium for intervention.

Therefore, strategic application of landscape character assessment in the existing spatial planning documents in Serbia can be recommended for the proper application of the European Landscape Convention. It represents a tool for testing the structuring capacity of the landscape features as a new infrastructure for urbanization. Landscape-based concepts propose spatial development which negotiates the contrasting realities of the urban/suburban/rural structures. Such 
an approach towards landscape interventions in a territory intertwined with water, forest and agriculture should result in a sustainable spatial structure that is capable of accepting and rationalizing new development trends and new production systems.
The challenge for further analysis would be to replicate and test the presented approach in a different context within the Serbian spatial planning policy framework and examining the approach in other countries with similar spatial planning system.

\section{References}

Ahern, J. (2011). From fail-safe to safe-to-fail: Sustainability and resilience in the new urban world. Landscape and Urban Planning, 100(4), 341-343.

Antrop, M (2000). Background concepts for integrated landscape analysis. Agriculture Ecosystems \& Environment, 77(1-2), 17-28.

Antrop, M. (2006a). From holistic landscape synthesis to transdisciplinary landscape management. In B. Tress, G. Tres, G. Fry, P.Opdam (Eds.). From Landscape Research to Landscape Planning: Aspects of Integration, Education and Application (Vol. 12, pp. 27-50). Dordrecht, NL: Springer.

Antrop, M. (2006b). Sustainable landscapes: contradiction, fiction or utopia?. Landscape and Urban Planning, 75(3-4), 187-197.

Antrop, M., \& Van Eetvelde, V. (2008). Mechanisms in recent landscape transformation. WIT Transaction on the Built Environment, 100, 183-192.

Corner, J. (2006). Terra Fluxus, In C.Waldheim (Ed.), The Landscape Urbanism Reader; New York, NYC: Princeton Architectural Press, pp. 21-33.

Council of Europe (2000). European Landscape Convention and Explanatory Report. Strasbourg. Council of Europe General directorate of Education, Culture, Sport and Youth and Environment, 200.0, Landscape Convention|T-LAND 06e.

De Montis, A. (2014). Impacts of the European Landscape Convention on national planning systems: A comparative investigation of six case studies. Landscape and Urban Planning, 124, 53-65.

Giddens, A. (1984). The Constitution of Society: Outline of the Theory of Structuration. Berkeley and Los Angeles, CA: University of California press.

Koolhaas, R. (1995). What Ever Happened to Urbanism? J. Sigler (Ed.). S,M,L,XL: O.M.A (pp. 959-971). New York, NYC: The Monicelli Press.

Mapire. (2018, February 22). The historical Map Portal, Austrian State Archives (Österreichisches Staatsarchiv). Retreived from http://mapire.eu/en/.

Mayer, E., (1997). The Expanded Field of Landscape Architecture. In G. F. Thompson, F. R. Steiner (Eds). Ecological Design and Planning. New York, NYC: John Willey \& Sons. INC. pp. 45-79.

Pihler, V., Vasiljevic, T.Z., \& Duncic, D. (2013). Water management, environmental protection and spatial planning reconciliation: "Accommodating" the
Danube and the Tisa river in Serbia. Spatium, 29, 49-52.

Roe, M., Jones, C., \& Mell,I.C. (2008). Final Report A Study for Natural: Research to Support the Implementation of the European Landscape Convention in England. England. Contract No. PYT02/10/1.16. Retrieved from https://www.academia.edu/download/8645595/elc-ne-research-march2008 tcm623598.pdf

Selman, P. (2006). Planning at the Landscape scale; London, UK: Routledge.

Selman, P. (2010). Landscape planning - preservation, conservation and sustainable development. Town Planning Review, 81(4). 381-406.

Semančíková, E., Dvočáková, Z., \& Líšková, V. (2007). How does strategic planning deal with spatial landscape problems? Proceedings of the Man in the landscape across frontiers: Landscape and land use change in Central European border regions. Conference Proceedings of the IGU/LUCC Central Europe Conference 2007. Charles University in Prague, Czech Republic: Faculty of Science pp.153163.

Steinitz, C. (2005). From Project to Global: on Landscape Planning and Scale. Landscape Review, 9(2). 117-127.

Swanwick, C., Herlin, I. S., \& Fairclough, G., (2002). Landscape Character Assessment, Guidelines for England and Scotland. Edinburgh, UK: The Countryside Agency, Cheltenham and Scottish Natural Heritage.

The Spatial Plan of the Republic of Serbia 2010-2020. Belgrade, RS: Official gazette of Republic of Serbia“, No. 88/10. Retrieved from: http://www.rapp.gov.rs/ en-GB/content/cid310/

Spatial Plan for the Special Purpose Area "The Cultural Landscape of Sremski Karlovci”, 2017, Urban and Spatial Planning Institute of Vojvodina, Novi Sad, APV: Official gazette of APV No 57/2017 Retrieved from: http://www.ekourbapv.vojvodina.gov. rs/wp-content/uploads/2018/08/Odluka-i-Plan-izSl-lista-1.pdf)

Van den Broeck, J. (2004). Strategic Structure Planning. A. Loeckx, K. Shannon, R. Tuts, H. Verschure (Eds.). Urban Trialogues: Visions, Projects, Co-productions. Localising Agenda 21. Nairobi, Kenya: 
UNCHS (United Nations Center for Human Settlements), pp. 168-184

Van Eetvelde, V., \& Antrop, M. (2007). Proceedings of the $18^{\text {th }}$ International Annual ECLAS Conference 2007: Landscape character beyond landscape typol- ogies. Methodological issues in trans-regional integration in Belgium. Belgrade, RS, pp. 229-239.

Vasiljevic, N. (2018). Landscape Planning: Theories and methodologies, Belgrade, Serbia: University of Belgrade - Faculty of Forestry. 